\title{
TRADUÇÃO E REVELAÇÃO: A RECEPÇÃO DOS NOMES DIVINOS NA TRADUÇÃ O DA ANTÍGONA DE SÓFOCLES POR HÖLDERLIN*
}

\author{
Gabriel Lago de Sousa Barroso $\star \star$ \\ Universidade Federal de Minas Gerais
}

\begin{abstract}
This paper aims to analyze the German poet Friedrich Hölderlin's reception of the Greek tragedy, by examining his translations of two of Sophocles' tragedies - Oedipus the King and Antigone-, which became a model for translation theory later on the 20th century. It intends to demonstrate Hölderlin's peculiar view of Greece, acknowledged in the background of his work, which is reflected on the religious patterns of his translation, as he emphasizes the divine elements of Sophocles' plays. This is more explicit in his transgressions of the original text, especially where he translates the Greek gods' names.
\end{abstract}

KEYWORDS: reception of classical Greece; Greek tragedy; German poetry; translation theory; Friedrich Hölderlin.

ste ensaio tem como objetivo analisar a recepção da tragédia grega na obra do poeta alemão Friedrich Hölderlin, principalmente a partir de uma análise de sua tradução de duas das tragédias de Sófocles Édipo Rei e Antígona - e de alguns de seus escritos teóricos, que lidam especificamente com o problema da tragédia grega. Minha intenção é observar o modo como se dá essa recepção para, em seguida, discutir o

\footnotetext{
* Uma versão prévia do presente trabalho foi apresentada no "XVIII Congresso Nacional de Estudos Clássicos" da Sociedade Brasileira de Estudos Clássicos (SBEC), realizado entre os dias 17 e 21 de outubro de 2011 na Universidade Federal do Rio de Janeiro (UFRJ).

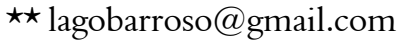


significado da Grécia Clássica para a Modernidade na obra de Hölderlin, bem como o sentido religioso da tragédia, que permite desvelar os limites do humano em seu contato com o divino. Analisarei, com essa finalidade, algumas passagens da tradução da Antígona, em especial nos atos III e IV, que correspondem aos versos 781 a 805 e 944 a 987 do original grego, na edição Oxford de Pearson. ${ }^{1}$

Hölderlin nasce em 1770 na região de Baden-Württemberg, no sul da Alemanha, e cursa o seminário na cidade de Tübingen. Lá tornase amigo de Schelling e Hegel, que se tornariam dois dos grandes nomes da filosofia alemã no século XIX. Porteriormente, em 1794, Hölderlin segue para Jena, onde frequenta as aulas do filósofo Fichte e entra em contato em Weimar com Goethe e Schiller. O próprio Hölderlin procura, nesse período, prosseguir na carreira acadêmica, buscando, sem sucesso, um posto na faculdade de filosofia de Jena. Ele segue então sua vida como poeta e filósofo até 1806, quando mergulha em um estado de profunda perturbação mental, permanecendo em uma clínica na cidade de Tübingen por mais de trinta anos, até a sua morte em 1843. As traduções destas duas tragédias de Sófocles - Édipo Rei e Antígona - foram, ao lado do romance Hyperion, as únicas obras publicadas em vida por Hölderlin, que permaneceu praticamente desconhecido na Europa até a reedição/ revisão de sua obra por Norbert von Hellingrath, iniciada somente em 1913.

As traduções são publicadas em 1804, portanto pouco antes de sua internação, sob o título de "As tragédias de Sófocles" (Die Trauerspiele des Sophokles), ${ }^{2}$ e a recepção é das piores possíveis. A versão possuía diversos erros e buscava soluções inexplicáveis na tradução do grego para o alemão. É famosa a anedota em que Johann Heinrich Voss - o célebre tradutor alemão da Odisseia e da Ilíada - expõe a versão a Goethe e Schiller, e Schiller dá largas risadas ao ler a obra de Hölderlin. Também Hegel e Schelling, os amigos do poeta, consideram sua versão de Sófocles a prova do avanço da patologia que não demoraria a afetá-lo.

Entretanto, com a reedição de von Hellingrath, a desdita das traduções de Hölderlin toma outro rumo. Acompanhando o surto de popularidade de sua obra poética, as traduções passam a ser cada vez mais lidas e, inclusive, encenadas. Assim é que, em 1923, Walter

\footnotetext{
${ }^{1}$ Cf. Sophoclis. Fabulae. Recognouit breuique adnotatione critica instruxit A. C. Pearson. Oxonii: E. Typographeo Clarendoniano, 1961.

${ }^{2}$ Cf. Hölderlin, F. Sämtliche Werke. Band 5: Übersetzungen. Org. Friedrich Beissner. Stuttgart: W. Kohlhammer Verlag, 1954.
} 
Benjamin, em seu famoso ensaio intitulado $A$ tarefa do tradutor, erige a tradução de Hölderlin à posição de "arquétipos de sua forma" (Urbilder ihrer Form $).{ }^{3}$ Bertolt Brecht prepara em 1948 uma montagem da Antígona traduzida por Hölderlin adaptada às necessidade cênicas. Carl Orff compõe em 1949 uma adaptação musical da tragédia de Sófocles a partir da versão do poeta alemão. O próprio Hellingrath, em um belo elogio às traduções, resume bem o significado que o projeto de Hölderlin teve para a crítica do século XX. A tradução demonstra, segundo ele:

[U]ma estranha mistura de familiaridade com a língua grega e compreensão viva de sua beleza e de seu caráter, com o desconhecimento de suas regras mais simples e uma total falta de exatidão gramatical. (...) Hölderlin como tradutor de Sófocles pode ser comparado àqueles escavadores do solo grego, desprovidos de formação sistemática, que se puseram a trabalhar com seus próprios recursos, com o coração cheio de entusiasmo e guiados por um grande instinto: extraviaramse muitas vezes e destruíram muita coisa, conseguiram, contudo, chegar até o fundo e pela primeira vez indicaram aos pósteros o caminho para as descobertas. ${ }^{4}$

Qual a razão para uma discordância tão profunda da crítica a esta tradução, entre os juízos de escárnio do século XIX e os de elogio do século XX? Quais elementos tornam tão polêmica e especial a relação linguística entre o ático de Sófocles e o alemão de Hölderlin?

Certamente, Hölderlin procurou com suas traduções estabelecer uma relação diferente com o mundo grego representado nas tragédias de Sófocles. A intenção de Hölderlin vai além da intenção tradicional do tradutor - a de, como afirma Walter Benjamin, tornar compreensível o texto em língua original em outra língua, pela "transposição mais exata possível da forma e do sentido do original". ${ }^{5}$ Neste sentido, inaugura-se uma maneira muito específica de se ver a recepção do mundo grego pelo mundo moderno, a qual Hölderlin trabalhará em sua poesia, mas que receberá sua formulação mais evidente no projeto de traduzir Sófocles. Essa recepção é, portanto, o primeiro elemento a ser observado

\footnotetext{
${ }^{3}$ Cf. Benjamin, W. A tarefa do tradutor. In: Gagnebin, J. M. (org.). Escritos sobre mito e linguagem (1915-1921). Trad. Susana Kampff Lages e Ernani Chaves. São Paulo: Duas Cidades/Ed. 34, 2011, p. 118.

${ }^{4}$ Cf. Hellingrath, apud Campos, H. A arte no horizonte do provável e outros ensaios. $3^{\mathrm{a}} \mathrm{ed}$. São Paulo: Perspectiva, 1975, p. 96-97.

${ }^{5}$ Cf. Benjamin, op. cit., p. 107.
} 
na obra de Hölderlin para que se possa então compreender o que pretendia com seu projeto de tradução.

Com respeito à intenção de Hölderlin, esta pode ser compreendida em duas declarações do poeta, colhidas à época da publicação das traduções: a primeira, em suas observações à sua versão de Antígona, afirma: "devemos apresentar, em toda parte, os mitos de forma mais demonstrável"; 6 a segunda, em uma carta ao seu editor Friedrich Wilmans, em que diz:

Eu espero apresentar a arte grega, que nos é estranha em virtude da conveniência nacional e dos erros com que sempre foi tratada, de modo mais vivo (lebendiger), mais vivo do que em geral se apresenta ao público, na medida em que eu marco o oriental que nela fora repudiado e aprimoro seus erros artísticos onde eles tenham ocorrido. ${ }^{7}$

Tornar o mito mais demonstrável, mais vivo: essa é a intenção que Hölderlin procura realizar por meio das traduções de Sófocles. Trata-se desde a origem de um projeto muito mais amplo que o de uma tradução convencional.

A relação com o mito - a recepção dos mitos gregos - encontrase no centro de seu projeto. Os mitos representados na tragédia não são para o poeta alemão um discurso estranho, longínquo, mas a cristalização de um elemento divino, da divindade que não deixa de existir no transcurso da História.

O que são precisamente para Hölderlin os deuses gregos, os deuses que perpassam todo o entrecho trágico? Difícil é decifrar esse enigma na obra do poeta. No entanto, pode-se dizer que em Hölderlin os deuses não são alegorias para os estados da alma humana, tampouco imaginações da fantasia, mas o próprio Ser, condensado em figuras objetivas, que por diversos modos se apresentam e vão de encontro aos homens marcados pela finitude e pela necessidade. ${ }^{8}$ Já se comparou a posição do poeta ao panteísmo - isto é, a identificação entre deus e

\footnotetext{
${ }^{6}$ Cf. Hölderlin, op. cit., 1954, p. 292: Wir müssen die Mythe nämlich überall beweisbarer darstellen (trad. minha).

${ }^{7}$ Cf. Hölderlin, F. Sämtliche Werke. Band 6: Briefe. Org. Friedrich Beissner. Stuttgart: W. Kohlhammer Verlag, 1959, p. 464: Ich hoffe, die griechische Kunst, die uns fremd ist, durch Nationalkonvenienz und Fehler, mit denen sie sich immer herumbeholfen hat, dadurch lebendiger als gewöhnlich dem Publikum darzustellen, daß ich das Orientalische, das sie verleugnet hat, mehr heraushebe, und ihren Kunstfehler, wo er vorkommt, verbessere (trad. minha).

${ }^{8}$ Cf. von Wiese, B. Die deutsche Tragödie von Lessing bis Hebbel. Hamburg: Hoffmann und Campe, 1983, p. 353.
} 
mundo - embora esse termo não seja o mais adequado para caracterizar seu pensamento. A verdadeira tarefa poética de Hölderlin é captar deus em um mundo em que deus se cala em silêncio e se encontra longe dos homens. Esse é o retrato do tempo que se enuncia ao poeta alemão, nos albores da Modernidade. Hölderlin é tão necessário a esse tempo quanto o padre é necessário no campo de batalha.

Esse deus oculto se abre para os olhos do poeta, o que permite a Hölderlin buscar na tradução algo mais que a transposição do texto grego para a língua alemã. Esse caráter divino da tragédia é exposto por Hölderlin em um escrito de 1799, intitulado Fundamento para o Empédocles:

O poema trágico oculta ainda mais [que a ode trágica] a intimidade (Innigkeit) na apresentação, a expressa em distinções mais fortes, porque expressa uma intimidade mais profunda, um divino mais infinito. (...) Também no poema trágico-dramático se exprime, portanto, o divino que o poeta sente e experimenta em seu mundo, também o poema trágico-dramático é para o poeta uma imagem do vivente que, para ele, é e era presente em sua vida. ${ }^{9}$

O divino presente no poema trágico-dramático entreabre-se para os olhos do poeta, pois o poeta encontra no trágico uma imagem semelhante ao divino de sua própria interioridade e de sua própria vida.

A iniciativa de Hölderlin, frente ao contexto literário e filosófico da Alemanha de então, principalmente no que concerne à recepção da tragédia grega, é única e original. De acordo com o crítico Benno von Wiese, grosso modo, podem-se observar nos séculos XVIII e XIX duas grandes linhas de interpretação da tragédia na Alemanha. Por um lado, a especulação idealista, que pensa a tragédia a partir de uma visão de mundo racionalista e a encara como um problema ético, que encontra sua superação em uma filosofia do espírito. A interpretação da Antígona de Sófocles por Hegel seria um exemplo desse modo de ver a aporia trágica. Por outro lado, a tradição romântica, que revaloriza na arte os elementos religiosos do período medieval e encara a tragédia a partir

\footnotetext{
${ }^{9}$ Cf. Hölderlin, F. Sämtliche Werke. Band 4: Der Tod des Empedokles; Aufsätze. Org. Friedrich Beissner. Stuttgart: W. Kohlhammer Verlag, 1962, p. 156: Das tragische Gedicht verhüllt die Innigkeit in der Darstellung noch mehr, drückt sie in stärkeren Unterscheidungen aus, weil es eine tiefere Innigkeit, ein unendlicheres Göttliches ausdrückt. (...) Auch im tragisch dramatischen Gedichte spricht sich also das Göttliche aus, das der Dichter in seiner Welt empfindet und erfährt, auch das tragisch dramatische Gedicht ist ihm ein Bild des Lebendigen, das ihm in seinem Leben gegenwärtig ist und war (trad. minha).
} 
da revelação do mundo cristão. Por essa via, a tragédia chega a ser encarada sob um viés religioso, mas predomina o elemento cristão, que dissolve a aporia trágica. ${ }^{10}$

Hölderlin, a partir de uma visão muito própria da natureza religiosa da tragédia, consegue compreender Sófocles de modo mais complexo, e encontrar uma via original ao mundo grego. Como afirma o filólogo Karl Reinhardt, isso leva Hölderlin a traduzir Sófocles de modo religioso, isto é, Hölderlin procura ressaltar o elemento divino por ele visto na tragédia, e por isso ele pode pretender tornar o mito "mais provável", "mais vivo" para seus contemporâneos. ${ }^{11}$

Naturalmente Hölderlin percebe que a era moderna em muito difere do mundo grego. Se a tragédia prova para ele que no mundo grego o homem se encontrava às voltas com o divino, que os deuses eram então próximos ao homem, o mundo moderno se encontra em oposição àquela realidade. A história do mundo é lida por Hölderlin conforme essa díade: há o tempo da proximidade de deus e o tempo do distanciamento de deus. Segundo afirma Wiese, os deuses podem estar "perto", e isso significa uma intensificação e elevação da vida, cujo verdadeiro nexo, que de outro modo permaneceria oculto, somente assim se torna visível. Na proximidade dos deuses, o homem é penetrado pelo Espírito, o qual o coloca no eternamente vívido, na real essência do Ser, seja de modo abençoado, seja de modo ameaçador. Eles podem, no entanto, estar também "longe", e isso não significa que não estejam disponíveis, mas que em determinadas eras eles estão ausentes e ocultos. A vida é então vivida pelos homens na inevitabilidade de suas contradições e cisões, e rechaça todo aquele vicejar espirituoso que a unidade com o espírito do Ser lhe garante. ${ }^{12}$

Não a proximidade dos deuses, mas a distância caracteriza os tempos modernos. Não a plenitude, mas a escassez do divino é o traço marcante de seu tempo. Somente ao poeta parece ainda se desvelar esse mundo de deuses de que falava a tragédia grega. Apenas o poeta pode ascender a estas alturas e admirá-las e, com seu canto, tentar trazêlas de volta a esse mundo desdivinizado.

Observando esses traços fundamentais da visão de mundo hölderliniana, suas traduções de Sófocles assumem uma nova amplitude.

\footnotetext{
${ }^{10}$ Cf. von Wiese, op. cit., p. 350-351.

${ }^{11}$ Cf. Reinhardt, K. Tradition und Geist. Gesammelte Essays zur Dichtung. Göttingen: Vandenhoeck \& Ruprecht, 1960, p. 382.

${ }^{12}$ Cf. von Wiese, op. cit., p. 353.
} 
Não se trata aqui de um projeto humanista ou filológico. Esse contato direto entre o poeta e o trágico permite a Hölderlin tentar traduzir as tragédias de Sófocles "por dentro", e transpor seu sentido imanente para o texto da tradução, revivificando na poesia da língua alemã toda a essência originária da poesia grega.

Também a polêmica relação entre antigos e modernos é aqui reformulada: não se trata mais de imitação ou de disputa com o mundo grego, mas de aprender no contato com esse mundo que aquilo que é próprio ao tempo do poeta deve ser por ele revelado. Como afirma em uma carta de dezembro de 1801 ao poeta e amigo Casimir Ulrich Boehlendorff: "Tenho elaborado desde há muito essa questão, e sei agora que não devemos tentar igualar nada aos gregos, a não ser o que, tanto para os gregos quanto para nós, deve constituir o mais elevado, a saber, a relação da vida e o destino". ${ }^{3}$

A carta de Hölderlin ao poeta Boehlendorff pode ser interpretada, por um lado, como a "superação do classicismo", como quer Peter Szondi. ${ }^{14}$ Por outro lado, demonstra uma identidade original com o mundo grego, que pode ser recuperada, ainda que por uma via diversa da imitação (Nachahmung), proposta por Winckelmann.

O projeto de Hölderlin de traduzir Sófocles é, nesse sentido, coerente tanto com a função profética que atribui ao poeta quanto com a visão profética que, enquanto poeta, ele antevê no futuro. Essa visão é exposta em poemas como Wie wenn am Feiertage... (Como quando em dia de festa...) e Ermunterung (Exortação). O poeta permanece em contato com o divino, mesmo que seu tempo se tenha afastado dos deuses. Seu canto tem a finalidade de guardar essa herança, mas também de anunciar um novo tempo.

Assim conclui no poema Exortação (primeira versão):

Ó esperança! breve, breve não cantarão sozinhos os bosques o elogio dos deuses, pois vem já o tempo em que da boca dos homens a alma, divina, de novo seja proclamada.

\footnotetext{
${ }^{13}$ Cf. Hölderlin, op. cit., 1959, p. 456: Ich habe lange daran laboriert und weiß nun, daß außer dem, was bei den Griechen und uns das Höchste sein muß, nämlich dem lebendigen Verhältniß und Geschik, wir nicht wohl etwas gleich mit ihnen haben dürfen (trad. minha).

${ }^{14}$ Cf. Szondi, P. Überwindung des Klassizismus: Der Brief an Böhlendorff vom 4. Dezember 1801. In: Bollack, J. et alii (org.) Schriften I. Frankfurt a.M.: Suhrkamp Verlag, 1978, p. 358.
} 
Em que nossos dias de novo, como flores sejam, onde, distribuído em rotação, o calmo Sol sua imagem do céu veja, e feliz nos felizes a luz se conheça.

Em que amoroso, em união com os mortais, o elemento então viva e então somente baste, no agradecer de crianças piedosas, a força da terra, que, infinita, se desenvolve,

e ele, que reina sem palavras, e o futuro desconhecido prepara, o deus, o espírito na palavra humana, em belos dias, outra vez com nomes, como outrora, seja dito. ${ }^{15}$

Em Como quando em dia de festa..., fica claro que a tarefa do poeta é uma tarefa ligada ao seu tempo e também ao seu povo, que é iluminado por suas palavras:

Pensamentos do espírito comum estão em silêncio se acabando, na alma do poeta,

desde longo tempo conhecida do infinito, subitamente tocada se estremece com a recordação, e a ela, inflamada pelo sagrado raio, fruto nascido do amor, obra de deuses e homens, o canto, que a ambos testemunha, alcança.

E por ele agora os filhos da terra

bebem sem perigo o fogo celeste.

mas cabe a nós, poetas!, permanecer com a cabeça descoberta debaixo das tormentas de deus,

\footnotetext{
${ }^{15}$ Cf. Hölderlin, F. Sämtliche Werke. Band 2: Gedichte nach 1800. Org. Friedrich Beissner. Stuttgart: W. Kohlhammer Verlag, 1953, p. 34-35: O Hoffnung! bald, bald singen die Haine nicht/ Der Götter Lob allein, denn es kommt die Zeit,/ Daß aus der Menschen Munde sich die/ Seele, die göttliche, neuverkündet.// Daß unsre Tage wieder, wie Blumen, sind,/Wo, ausgeteilt im Wechsel, ihr Ebenbild/Des Himmels stille Sonne sieht und/Froh in den Frohen das Licht sich kennet,// Daß liebender, im Bunde mit Sterblichen/Das Element dann lebet und dann erst reich,/ Beifrommer Kinder Dank, der Erde/ Kraft, die unendliche, sich entfaltet,// Und er, der sprachlos waltet, und unbekannt/Zukünftiges bereitet, der Gott, der Geist/ Im Menschenwort, am schönen Tage/ Wieder mit Namen, wie einst, sich nennet (trad. minha).
} 
empunhar com nossas próprias mãos

o raio mesmo do pai e

entregar ao povo, envolto

no canto, o dom celeste. ${ }^{16}$

Somente a partir do conhecimento das funções que Hölderlin atribui ao poeta pode-se compreender sua carta ao editor, em que afirma procurar marcar "o oriental" que fora repudiado na tragédia grega. Oriental aqui não se refere ao Oriente geográfico como por nós hoje compreendido - o Oriente-Médio, a Índia etc. O oriental possui em Hölderlin o sentido de originário, próximo de deus, imediato, que ele procurará marcar em sua poesia, de modo a tornar o mito mais vivo.

Essa conexão direta com os aspectos divinos da tragédia resulta, na tradução de Hölderlin, em diversas transgressões do original grego, intensamente polêmicas para os fundamentos da tradução de sua época. Foram essas transgressões do texto grego - aliadas, claro, ao fato de que Hölderlin tinha um conhecimento regular da língua grega - que causaram o julgamento tão negativo de sua época, manifesto no riso de Schiller. Por outro lado, também essas transgressões, juntamente ao experimento poético de traduzir a tragédia para a forma de hino característica da poesia de Hölderlin, tornaram suas traduções de Sófocles tão célebres no século passado.

Ressaltaremos aqui apenas um dos traços da tradução de Hölderlin, em que fica evidente a originalidade de sua versão. Refirome às traduções dos nomes dos deuses gregos, que Hölderlin altera propositalmente em sua versão, de modo a revelar a sua essência, em conformidade com sua visão de mundo religiosa.

Nos versos 781 e 782 da Antígona de Sófocles, o coro de anciões tebanos canta o amor de Hêmon por Antígona, entoando o nome de Eros. No original encontramos:

\footnotetext{
${ }^{16}$ Cf. Hölderlin, op. cit., 1953, p. 123-124: Des gemeinsamen Geistes Gedanken sind,/ Still endend, in der Seele des Dichters,// Daß schnellbetroffen sie, Unendlichem/Bekannt seit langer Zeit, von Erinnerung/ Erbebt, und ihr, von heilgem Strahl entzündet,/ Die Frucht in Liebe geboren, der Götter und Menschen Werk,/ Der Gesang, damit er beiden zeuge, glückt./ (...)/ Und daher trinken himmlisches Feuer jetzt/ Die Erdensöhne ohne Gefahr./ Doch uns gebührt es, unter Gottes Gewittern,/Ihr Dichter! mit entblößtem Haupte zu stehen,/Des Vaters Strahl, ihn selbst, mit eigner Hand/Zu fassen und dem Volk ins Lied/Gehüllt die himmlische Gabe zu reichen (trad. minha).
} 
Eros, invencível em combate,

Eros, que cai sobre a riqueza... ${ }^{17}$

Hölderlin faz a seguinte tradução do mesmo trecho:

Espírito do amor, contudo em combate, sempre vencedor! Tu, Espírito da Paz, que cochilas sobre o comércio. ${ }^{18}$

Como se vê, Sófocles se refere duas vezes a Eros, mas Hölderlin vai propositalmente além do texto, traduzindo o nome do deus ora por "Espírito do amor", ora por "Espírito da paz".

Em outro trecho mais notório, nos versos 947-950, também da Antígona, o coro invoca Zeus ao falar do infortúnio da condenação de Antígona por Creonte, comparando-a com Dânae. Cito:

E era ela de estimada

linhagem, ó filha,

e de Zeus guardava o tesouro,

a semente caída em chuva de ouro. ${ }^{19}$

Hölderlin modifica - ou "revela" - o original em sua tradução:

Embora de nobre linhagem, ó filha,

ela contava ao Pai do Tempo

o bater das horas, o dourado. ${ }^{20}$

Hölderlin subverte completamente o original de Sófocles, conscientemente, para atender às finalidades de sua tradução. Substitui o nome de Zeus por "Pai do Tempo", e reinterpreta o mito de Dânae, colocando-a não como guardiã da semente de Zeus, mas como aquela que conta cada um dos batimentos dourados das horas.

Em suas observações à tradução de Antígona, Hölderlin justifica expressamente sua escolha, como modo de "aproximá-la de seu modo de representação". E afirma:

\footnotetext{
${ }^{17}$ Antígona, v. 781-782: Éros aníkate mákhan,/Éros, hòs en kténesi pípteis (trad. minha).

${ }^{18}$ Cf. Hölderlin, op. cit., 1954, p. 259: Geist der Liebe, dennoch Sieger/Immer, in Streit! Du Friedensgeist, der über/ Gewerb einnicket (trad. minha).

${ }^{19}$ Antígona, v. 947-950: Kaítoi kaì geneâi tímios, ô paî pâ̂,/kaì Zenòs tamieúeske gonàs khrysorýtous (trad. minha).

${ }^{20}$ Cf. Hölderlin, op. cit., 1954, p. 266: Obgleich an Geschlecht edel, o Kind!/ Sie zählete dem Vater der Zeit/ Die Stundenschläge, die goldnen (trad. minha).
} 
De forma determinada ou indeterminada, é Zeus que deve ser dito. Com seriedade, preferencialmente: Pai do tempo ou Pai da terra, porque o seu caráter consiste em, por oposição à eterna tendência, inverter a aspiração de abandonar este mundo em direção ao outro na aspiração de passar do outro mundo para este. É preciso, de fato, apresentar o mito sempre da forma mais demonstrável. O devir, em seu fluxo dourado, significa o raio de luz, que também a Zeus pertence, na medida em que o tempo, que será marcado, é calculável por meio de tais raios. Assim será sempre quando o tempo for contado na dor, porque então o ânimo pode seguir, com simpatia, a mudança do tempo, e assim captar a simples passagem das horas, livre do entendimento que só conclui do presente para o futuro. ${ }^{21}$

O caráter descrito seria a essência de Zeus, e por isso seu nome deve ser dito "Pai do Tempo". Por meio de seus raios de luz, Zeus ligase ao tempo, que é calculável mediante esses raios. Não o tempo do entendimento, que Hölderlin critica, mas o tempo "contado no sofrimento", o verdadeiro compreender do tempo, que o capta como "simples curso das horas", o dourado "bater das horas".

Não cabe, neste momento, discutir o conteúdo da "revelação" de Hölderlin da essência de Zeus. Sua intenção é poético-profética: ele não pretende se prender às linhas do texto, mas procede por meio dessa revelação da essência original. ${ }^{22}$ Procura, sim, a partir de uma visão pressuposta da tarefa da poesia, recuperar o divino perdido no mundo moderno por meio da ligação reveladora do poeta com o divino

${ }^{21}$ Cf. Hölderlin, op. cit., 1954, p. 292: Im Bestimmteren oder Unbestimmteren muß wohl Zevs gesagt werden. Im Ernste lieber: Vater der Zeit oder: Vater der Erde, weil sein Charakter ist, der ewigen Tendenz entgegen, das Streben aus dieser Welt in die andre zu kehren zu einem Streben aus einer andern Welt in diese. Wir müssen die Mythe nämlich überall beweisbarer darstellen. Das goldenströmende Werden bedeutet wohl die Strahlen des Lichts, die auch dem Zevs gehören, insofern die Zeit, die bezeichnet wird, durch solche Strahlen berechenbarer ist. Das ist sie aber immer, wenn die Zeit im Leiden gezählt wird, weil dann das Gemiut vielmehr dem Wandel der Zeit mitfühlend folget, und so den einfachen Stundengang begreift, nicht aber der Verstand von Gegenwart aufdie Zukunft schließt (trad. e grifo meus).

${ }^{22}$ Antoine Berman parece compreender as traduções de Hölderlin também nesse sentido, e por isso fala de uma "verdade da tradução". As traduções de Hölderlin não seriam nem transformação literária das obras traduzidas, nem reprodução, mas teriam como finalidade "atualizar o conflito que é a vida destas obras". Essa seria a lição deixada pelo poeta à reflexão do tradutor (cf. Berman, A. A tradução e a letra, ou, O albergue do longínquo. Trad. Marie-Hélène Catherine Torres, Mauri Furlan, Andréia Guerini. Rio de Janeiro: 7Letras, 2007, p. 89). 
da tragédia. O único meio possível para isso é se a tradução se converter em algo mais que tradução, isto é, se ascender a revelação. Somente isso autoriza Hölderlin a transgredir o texto: transgredir para expor o que nele se encontra oculto. A tarefa do tradutor do mito torna-se uma tarefa possível somente àquele que traduz para revelar - ao poeta cabe desvelar o divino da tragédia.

$\mathrm{Na}$ obra de Hölderlin - em especial nas traduções de Sófocles o próprio conceito de recepção é levado a um limite radical, vez que o poeta traça uma linha direta de ligação com o mito grego. A recepção não se resume ao aspecto externo, à recepção de obras fechadas em si, em que se reconhece a alteridade da cultura grega frente ao mundo moderno. As traduções de Édipo Rei e Antígona - ao contrário - devem recuperar o divino em um mundo desdivinizado; recuperar o nome de deus em um mundo que já não pode dizê-lo. Por isso, não se trata de um aspecto marginal da obra de Hölderlin, ou mesmo secundário da poesia moderna, mas de um ponto central, em que o reencontro com a Grécia e a tragédia alcança sua forma mais profunda.

\section{Referências}

BENJAMIN, W. A tarefa do tradutor. In: GAGNEBIN, J. M. (org.). Escritos sobre mito e linguagem (1915-1921). Trad. Susana Kampff Lages e Ernani Chaves. São Paulo: Duas Cidades/Ed. 34, 2011.

BERMAN, A. A tradução e a letra, ou, O albergue do longínquo. Trad. Marie-Hélène Catherine Torres, Mauri Furlan, Andréia Guerini. Rio de Janeiro: 7Letras, 2007.

de CAMPOS, H. $A$ arte no horizonte do provável e outros ensaios. $3^{\mathrm{a}}$ ed. São Paulo: Perspectiva, 1975.

HÖLDERLIN, F. Ensayos. $6^{a}$ ed. Trad. Felipe Martínez Marzoa. Madrid: Hiperión, 2008.

. Sämtliche Werke. Band 2: Gedichte nach 1800. Org. Friedrich Beissner. Stuttgart: W. Kohlhammer Verlag, 1953.

. Sämtliche Werke. Band 4: Der Tod des Empedokles; Aufsätze. Org. Friedrich Beissner. Stuttgart: W. Kohlhammer Verlag, 1962.

. Sämtliche Werke. Band 5: Übersetzungen. Org. Friedrich Beissner. Stuttgart: W. Kohlhammer Verlag, 1954.

. Sämtliche Werke. Band 6: Briefe. Org. Friedrich Beissner. Stuttgart: W. Kohlhammer Verlag, 1959.

REINHARDT, K. Tradition und Geist. Gesammelte Essays zur Dichtung. Göttingen: Vandenhoeck \& Ruprecht, 1960. 
SOPHOCLIS. Fabulae. Recognouit breuique adnotatione critica instruxit A. C. Pearson. Oxonii: E. Typographeo Clarendoniano, 1961.

SZONDI, P. Überwindung des Klassizismus: Der Brief an Böhlendorff vom 4. Dezember 1801. In: BOLLACK, Jean et alii (org.). Schriften I. Frankfurt a.M.: Suhrkamp Verlag, 1978.

von WIESE, B. Die deutsche Tragödie von Lessing bis Hebbel. Hamburg: Hoffmann und Campe, 1983. 